\title{
Trajetória da escolarização de jovens e adultos no Brasil: de plataformas de governo a
}

propostas pedagógicas esvaziadas

- Márcia Friedrich *

- Anna M. Canavarro Benite "*

- Claudio R. Machado Benite "**

- Viviane Soares Pereira "*n-

\section{Resumo}

Este artigo traz uma abordagem histórica da Escolarização de Jovens e Adultos e sua trajetória na história da educação no Brasil. Caracteriza-se por uma análise documental sobre o movimento desta modalidade de ensino e as politicas públicas que a regem. Fazemos um paralelo com a evolução histórica, formação de professores, mercado de trabalho no Brasil, utilizando fontes primárias e secundárias de pesquisa, compreendendo o período de 1973 até 2007. Constatamos que a literatura especializada, em geral, descreve acontecimentos cronológicos de iniciativas pontuais na tentativa de solucionar os problemas decorrentes do analfabetismo e falta de qualificação da mão de obra necessária ao modo de produção vigente em cada época, como iniciativas em relação às políticas públicas. No que diz respeito à relação com as propostas pedagógicas para esta modalidade de ensino, com base na análise de documentos legais, diretrizes e programas para o contexto educacional brasileiro, estas se caracterizam por uma educação compensatória, supletiva e emergencial.

Palavras-chave: Escolarização de Jovens e Adultos. Público de EJA. Políticas públicas. Propostas pedagógicas.

Mestre em Educação em Ciências e Matemática, Universidade Federal de Goiás (UFG); Professora da Rede Municipal de Educação de Goiânia. E-mail: marcia.friedrich@gmail.com

.. Doutora em Ciências, UFG. E-mail: anna@quimica.ufg.br

… Doutorando em Química, Mestre em Ciências e Matemática, Laboratório de Pesquisas em Educação Química e Inclusão (LPEQI/UFG). E-mail: claudio.benite@ueg.br

.... Licenciada em Química, Universidade Estadual de Goiás (UEG), Laboratório de Pesquisas em Educação Química e Inclusão (LPEQI/UFG). E-mail: vyvyane30@yahoo.com.br 


\section{Trajectory schooling of youth and adults in Brazil: of government platforms to the pedagogical proposals emptied \\ Abstract}

This article provides a historical approach of Schooling for Youth and Adults and its trajectory in the history of education in Brazil. It is characterized by an analysis documentary on the movement of this type of education and public policies that govern it. We compare with the historical development, teacher training, the labor market in Brazil, using primary and secondary sources with the search including the period from 1973 to 2007. We note that literature in general, describes events chronologically ad hoc initiatives in an attempt to solve the problems of illiteracy and lack of qualification of the workforce necessary for the current method of production each season, as initiatives for public policies. Regarding the relationship with the educational proposals for this type of education based on the analysis of legal documents, guidelines and programs for the Brazilian educational context, they are characterized by a compensatory, supplementary, and emergency education. Keywords: Schooling for Youth and Adults. Public EJA. Public Policy. Educational Proposals.

\section{Trayectoria de la escolarización de jóvenes y adultos en Brasil: de plataformas de gobierno a propuestas pedagógicas vaciadas Resumen}

Este artículo ofrece un enfoque histórico de la escolarización de jóvenes y adultos y su trayectoria en la historia de la educación en Brasil. Se caracteriza por un análisis documental sobre el movimiento de este tipo de educación y las políticas públicas que la rigen. Hacemos un paralelismo con la evolución histórica, la formación del profesorado, el mercado de trabajo en Brasil, utilizando fuentes primarias y secundarias de pesquisa incluyendo el período de 1973 a 2007. Tomamos nota de que la literatura, en general, describe cronológicamente los acontecimientos de iniciativas puntuales en un intento de resolver los problemas del analfabetismo y la falta de calificación de la mano de obra necesaria para el modo de producción de cada época, como las iniciativas con relación a las políticas públicas. Cuanto a la relación con las propuestas educativas para este tipo de educación basado en el análisis de documentos jurídicos, directrices y programas para el contexto educativo brasileño, estas se caracterizan por una educación compensatoria, y complementaria de emergencia.

Palabras clave: La escolarización de jóvenes y adultos. Público de EJA. Las políticas públicas. Propuestas pedagógicas. 


\section{Caracterizando a pesquisa}

Este trabalho traz uma abordagem da Escolarização de Jovens e Adultos e sua trajetória na história da educação no Brasil. Caracteriza-se por uma análise documental da literatura de Educação de Jovens e Adultos (EJA) e do movimento da modalidade de ensino, políticas públicas, bem como o seu percurso na formação de professores. Fazendo um paralelo com a evolução histórica, formação de professores, mercado de trabalho no Brasil, trabalhamos com fontes primárias e secundárias de pesquisa, compreendendo o período de 1973 até 2007.

Nossa trajetória metodológica consistiu em estudos baseados em documentos como material primordial, fossem revisões bibliográficas, fossem pesquisas historiográficas, e tentamos extrair destes uma análise, organizando-os e interpretandoos segundo os objetivos da investigação proposta. 0 trabalho analítico teve como objeto central a produção escrita sobre EJA no período investigado, bem como referências sócio-históricas que influenciaram estas produções.

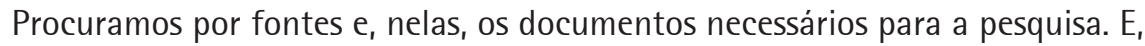
em um primeiro momento, não nos preocupamos com a análise propriamente dita, que seria núcleo do trabalho subsequente, mas com a organização do material. Para isso, importou somente a obtenção de informações advindas de publicações, anais de congressos, além de referências sobre o tema. As fontes foram anotadas e a documentação arquivada em pastas, segundo ordem cronológica ao mesmo tempo em que se dava prosseguimento à coleta.

Leituras e fichamentos tiveram papel central na adoção desta técnica de pesquisa. Então, para cada documento criamos uma ficha contendo resumo, referência bibliográfica da publicação, além de algumas transcrições de trechos que poderiam ser utilizados posteriormente. Processamos esta organização do material seguindo critérios da análise de conteúdo (BARDIN, 1994). Para desenvolver a análise, além de contar com a organização da documentação foram construídos quadros de autores considerados referenciais na área, dentre os quais: Vanilda Pereira Paiva (1973), Celso de Rui Beisiegel (1974), Maria Margarida Machado (1998, 2000), Maria Clarice Vieira (2004), Marta Kohl de Oliveira (1999), Paulo Freire $(1983,1987$, 2002), Moacir Gadotti e José Eustáquio Romão (2006), Gaudêncio Frigotto, Maria Ciavatta e Marise Ramos (2005), José Eustáquio Romão (2006), Sérgio Haddad e Maria Clara Di Pierro (2000), Selva Paraguassú Lopes e Maria Ciavatta (2005), Maria Clara Di Pierro, Orlando Joia e Vera Masagão Ribeiro (2001), Osmar Fávero, Sonia Maria Rummert e Sonia Maria Vargas (1999), Sonia Maria Rummert e Jaqueline Pereira Ventura (2007) entre outros.

0 objetivo da pesquisa é analisar historicamente a articulação entre as políticas públicas e suas propostas pedagógicas na EJA, no Brasil. No presente estudo, cons- 
tatamos que a literatura traz em geral acontecimentos cronológicos de iniciativas pontuais na tentativa de solucionar os problemas decorrentes do analfabetismo e falta de qualificação da mão de obra necessária ao modo de produção em cada época da história de nosso país. Também se caracteriza por uma educação compensatória, supletiva e emergencial. Quanto aos professores surge um sujeito com perfil de um herói que resolve enfrentar sem uma formação específica uma modalidade de ensino com muitas carências. 0 professor diante de manuais precisa usar de toda sua criatividade para ensinar ao seu aluno, também numa condição de exclusão. A inquietação das universidades com esse tipo de formação somente agora começa a se manifestar e isso impulsiona ingenuamente a criação em seus cursos de disciplinas que abordem o tema EJA.

\section{Um pequeno glossário sobre a EJA}

A EJA emerge de lacunas do sistema educacional regular (processo de escolarização) e compreende um conjunto muito diverso de processos e práticas formais e informais relacionadas à aquisição ou ampliação de conhecimentos básicos, de competências técnicas e profissionais ou de habilidades socioculturais.

Muitos destes processos se desenvolvem de modo mais ou menos sistemático fora de ambientes escolares, realizando-se na família, nos locais de trabalho, nos espaços de convívio socioculturais e lazer, nas instituições religiosas e, nos dias atuais, também com o concurso dos meios de informação e comunicação à distância. (HADDAD; DI PIERRO, 2000, p. 4).

Concordamos com Haddad e Di Pierro (2000) que qualquer tentativa de historiar um universo tão plural de práticas formativas implicaria risco de fracasso, pois a EJA estende-se por quase todos os domínios da vida social. Assim, o texto que segue aborda os processos sistemáticos e organizados de formação geral de pessoas jovens e adultas no Brasil, conferindo especial atenção à educação escolar, ou seja, à escolarização de jovens e adultos.

Por sua vez, a escolarização de jovens e adultos pode ser considerada em toda sua trajetória como proposta política redimensionada à plataforma de governo na tentativa de elucidação de um problema decorrente das lacunas do sistema de ensino regular. Sendo assim, muitas confusões surgem nas definições encontradas na literatura acerca da nomenclatura de EJA. Não significa que essa modalidade de ensino, hoje Educação de Jovens e Adultos, tenha diferentes definições, mas pela própria história da evolução da EJA no Brasil e no mundo nas diferentes faces do desenvolvimento histórico da sociedade, o tratamento dos termos associados foi-se confundindo e se configurando como complementação de estudos e suplementação de escolarização. 
Segundo Gadotti e Romão (2006), os termos educação de adultos, educação popular, educação não-formal e educação comunitária são usados como sinônimos, mas não o são. A educação de adultos caracteriza-se pela postura da United Nations Education Social and Cultural Organization (UNESCO) reportando-se a uma área especializada da educação. Educação não formal é utilizada pelos Estados Unidos para fazer referência à educação de adultos dos países de terceiro mundo, onde reserva-se o uso do termo educação de adultos (GADOTTI; ROMÃO, 2006).

No Brasil, o termo educação não formal acompanha o conceito difundido na América Latina que se dirige à educação de adultos vinculada a organismos não governamentais, geralmente locais onde o Estado se omitiu. Assim, está desenvolvida e organizada em caráter de não parceria com os organismos formais. A educação popular caracteriza-se pela compreensão contrária à educação de adultos impulsionada pelos organismos oficiais, surgindo nos espaços em que a necessidade dos grupos aflora e o Estado não tem intenção nem força para atuar. A característica da educação popular brota com o entendimento da conscientização de Paulo Freire e um profundo respeito aos saberes populares (GADOTTI; ROMÃO, 2006).

Com o processo de industrialização e a criação do Serviço Nacional de Aprendizagem Industrial (SENAI)' em 1942, a educação profissional passa a ser vislumbrada como importante veículo para que os cidadãos tenham acesso às conquistas tecnológicas da sociedade como um todo, instrumento para a compreensão do processo produtivo, como instrumento de apropriação do saber tecnológico, de reelaboração da cultura do trabalho, de domínio e geração do conhecimento no seu campo profissional que deve vincular-se ao mundo do trabalho e à prática social. É nesse momento que a qualificação profissional passa a se instituir dentro da EJA.

Em outra perspectiva, a EJA também pode ser confundida, não raramente, com a educação inclusiva. Nesse sentido, cabe aqui um novo esclarecimento. A partir da Conferência Mundial de 1994 da UNESCO sobre Necessidades Educacionais Especiais (Liga Internacional das Sociedades para Pessoas com Deficiência Mental, 1994) o ensino inclusivo é definido, num sentido mais amplo, como:

[...] a prática da inclusão de todos - independentemente de seu talento, deficiência, origem socioeconômica ou origem cultural - em escolas e salas de aula provedoras, onde todas as necessidades dos alunos são satisfeitas (KARAGIANNIS; STAINBACK, W.; STAINBACK, S., 1999, p. 21).

\footnotetext{
Serviço Nacional de Aprendizagem Industrial (SENAI), criado em 1942, pelo Decreto-Lei ${ }^{\circ} .4 .048$, do então presidente Getúlio Vargas, surgiu para atender a uma necessidade premente: a formação de mão de obra para a incipiente indústria de base (SENAI, [2007?]).
} 
Em todos os casos, assistimos a hegemonia do Estado atuando de forma marcante por contradições sociais (GADOTI; ROMÃO, 2006) e políticas públicas fragmentadas além da falta de integração entre outras políticas, tais como a inserção profissional e melhoria de renda das familias, etc. (FRIGOTT0; CIAVATA; RAMOS, 2005).

\section{Trajetória histórica da escolarização de jovens e adultos no Brasil}

0 histórico da EJA no Brasil perpassa a trajetória do próprio desenvolvimento da educação e vem institucionalizando-se desde a catequização dos indígenas, a alfabetização e a transmissão da língua portuguesa servindo como elemento de aculturação² dos nativos (PAIVA, 1973).

Com a vinda da família real para o Brasil, surgiu a necessidade da formação de trabalhadores para atender a aristocracia portuguesa e, com isso, implantou-se o processo de escolarização de adultos com o objetivo de servirem como serviçais da corte e para cumprir as tarefas exigidas pelo Estado. Segundo Piletti (1988, p. 165) "a realeza procurava facilitar o trabalho missionário da igreja, na medida em que esta procurava converter os índios aos costumes da Coroa Portuguesa".

Em 1854 surgiu a primeira escola noturna no Brasil cujo intuito era de alfabetizar os trabalhadores analfabetos, expandindo-se muito rapidamente. Até 1874 já existiam 117 escolas, sendo que as mesmas possuiam fins específicos, como por exemplo: no Pará para a alfabetização de indígenas e no Maranhão para esclarecer colonos de seus direitos e deveres (PAIVA, 1973).

Em nove de janeiro de 1881 foi concebido o Decreto $n^{\circ} 3.029$, conhecido como "Lei Saraiva" em homenagem ao Ministro do Império José Antônio Saraiva, que foi o responsável pela primeira reforma eleitoral do Brasil instituindo pela primeira vez, 0 "título de eleitor". Esta Lei proibia o voto dos analfabetos por considerar a educação como ascensão social. 0 analfabetismo, então, estava associado à incapacidade e à inabilidade social. A expulsão dos jesuitas no século XVIII desestruturou o ensino de adultos neste propósito, discussão esta que foi retomada no Império (PAIVA, 1973).

Nos anos de transição do Império-República (1887-1897), a educação foi considerada como redentora dos problemas da nação. Houve a expansão da rede escolar, e as "ligas contra o analfabetismo", surgidas em 1910, que visavam à imediata supressão do analfabetismo, vislumbraram o voto do analfabeto (PAIVA, 1973). 0

\footnotetext{
2 A absorção de uma cultura pela outra, onde essa nova cultura terá aspectos da cultura inicial e da cultura absorvida. "através das crianças os jesuítas buscavam atingir seus pais; além disso , era tentada a catequese direta dos indígenas adultos e nesses casos a alfabetização e transmissão do idioma português servia como instrumento de cristianização e aculturação dos nativos” ( PAIVA, 1973, p. 165).
} 
caráter qualitativo e a otimização do ensino tiveram como palco as melhorias das condições didáticas e pedagógicas da rede escolar, quando foram iniciadas mobilizações em torno da educação como dever do Estado, sendo este um período de intensos debates políticos.

Estas discussões se intensificaram nas décadas de 20 e 30, com a Revolução de 30 com as mudanças políticas e econômicas e o processo de industrialização no Brasil a EJA começa a marcar seu espaço na história da educação brasileira:

As reformas da década de 20 tratam da educação dos adultos ao mesmo tempo em que cuidam da renovação dos sistemas de um modo geral. Somente na reforma de 28 do Distrito Federal ela recebe mais ênfase, renovando-se o ensino dos adultos na primeira metade dos anos 30 (PAIVA, 1973, p. 168).

Com a criação do Plano Nacional de Educação instituido na Constituição de 1934, estabeleceu-se como dever do Estado o ensino primário integral, gratuito, de frequência obrigatória e extensiva para adultos como direito constitucional. A oferta de ensino básico e gratuito estendeu-se a praticamente todos os setores sociais.

A década de 40 foi marcada por grandes transformações e iniciativas que possibilitaram avanços significativos na educação e por consequência na EJA. A criação do Serviço Nacional de Aprendizagem Industrial (SENAI) vem corroborar com a intenção da sociedade capitalista e dos grupos econômicos dominantes: sem educação profissional não haveria desenvolvimento industrial para o país. Vincula-se neste momento a educação de adultos à educação profissional (GADOTI; ROMÃO, 2006). Nessa fase da história, a educação é considerada como fator de segurança nacional tendo em vista o alto índice de analfabetismo: aproximadamente 50\% da população em 1945. Nesse período a estagnação econômica, foi relacionada à falta de educação escolar do seu povo.

Também na década de 40 foi regulamentado o Fundo Nacional de Ensino Primário (FNEP), criado pelo professor Anísio Teixeira ${ }^{3}$. Esse fundo tinha como objetivo garantir recursos permanentes para o ensino primário. Anísio Teixeira se preocupava com a desigualdade econômica e cultural reinante entre os municipios, o que ocasionava a formação desigual dos alunos. Para que essa desigualdade fosse amenizada propôs a criação de um "custo padrão", com o objetivo de redistribuir entre municípios de um estado da federação os recursos já existentes para a educação fundamental, a partir da pré-fixação de um custo médio anual, nacional, do aluno financiado pelos três poderes públicos: União, Estados e Municípios (AMARAL, 2001). A criação do Instituto Nacional de Estudos e Pesquisas Educacionais Anísio Teixeira (INEP), organismo

30 professor Anísio Teixeira, na década de 1960, apresentou uma proposta de como definir e implantar um fundo que garantisse recursos permanentes para o ensino primário. (AMARAL, 2001, p. 278). 
responsável pelo incentivo e realização de estudos na área da educação data dessa década. Outro marco desta trajetória foi a Campanha de Educação de Adolescentes e Adultos (CEAA) na qual se começou a pensar o material didático para a educação de adultos. Este foi seguido por outros fatores da estruturação da EJA tais como: a realização do $1^{\circ}$ Congresso Nacional de Educação de Adultos ${ }^{4}$ em 1947 e do Seminário Interamericano de Educação de Adultos, em $1949^{5}$.

Como plataforma política de governo de Getúlio Vargas (pensada por Lourenço Filho) ${ }^{6}$ a educação de adultos foi entendida como peça fundamental na elevação dos níveis de escolarização da população em seu conjunto, compreendendo este processo como fundamental para a elevação do nível cultural dos cidadãos (BEISEIGEL, 1974). Desta forma, foram organizadas escolas em locais diversos, tal movimento ficou conhecido como Educação de Várzea. A proposta era um currículo básico visando também à expansão agrícola. Essa ação ficou restrita à alfabetização e por isso foi também denominada "Fábrica de Leitores". Lourenço Filho, para refazer as bases eleitorais, estendeu as escolas para o interior do Brasil e com essa ação ficou a certeza de que somente a alfabetização não resolveria, era preciso uma ação mais ampla junto às comunidades (DI PIERRO; JOIA; RIBEIRO, 2001).

Em 1958, Juscelino Kubitscheck de Oliveira, então presidente da república, convoca grupos de vários estados para relatarem suas experiências no "Congresso de Educação de Adultos". Nesse congresso ganha destaque a experiência do grupo de Pernambuco liderado por Paulo Freire (GADOTI, 2000). Este grupo se constituía em um movimento de educação voltado para o desenvolvimento da educação de adultos, com críticas muito fortes à precariedade dos prédios escolares, a inadequação do material didático e à qualificação do professor. 0 momento também se caracterizou por inovações pedagógicas enfatizando uma educação com o homem e não para o homem. Propunha uma renovação dos métodos e processos educativos, abandonando os processos estritamente auditivos em que o discurso seria substituído pela discussão e participação do grupo (PAIVA, 1973).

\footnotetext{
${ }^{4}$ Realizou-se a primeira avaliação sobre o enorme índice de analfabetismo no país, passou-se já a interpretar a EJA como algo bem maior do que a simples transmissão de técnicas elementares da leitura e da escrita, além de se discutir a necessidade de uma diferenciação metodológica para a EJA, levandose em consideração o meio rural e urbano (OLIVEIRA; ALMEIDA, 2005, p. 2).

${ }^{5}$ Seminário Interamericano de Educação, promovido pela UNESCO e pela OEA em 1949, com sede no Rio de Janeiro, configurou-se como momento de reflexão, planejamento e sistematização de diretrizes que projetaram o conjunto inicial de práticas em Educação Rural estendidas pelos anos 50. Como objetivo geral, o Seminário estabeleceu para si o compromisso com a construção de uma "nova vida internacional", com formação de uma "cultura americana", com a estruturação política e econômica do continente, com a convivência civil e a participação democrática de todos no bem estar geral, além do compromisso central, que era o da incorporação das massas indigenas e rurais à vida nacional e o "cumprimento da missão histórica da América em construir uma pátria aberta a todos os perseguidos da terra" (SOUZA, 1999).

${ }^{6}$ Educador brasileiro conhecido, sobretudo por sua participação no movimento dos pioneiros da Escola Nova, recebeu duras críticas por ter colaborado com o Estado Novo de Getúlio Vargas (DI PIERRO; JOIA; RIBEIRO, 2001).
} 
O Governo de Juscelino Kubitscheck de Oliveira instituia-se como preocupado com a conscientização do povo brasileiro e com a participação da população mais pobre, em um esforço conjunto para a construção do país. Assim, criou a Campanha Nacional de Erradicação do Analfabetismo (CNEA) com o objetivo de diminuir os índices do analfabetismo, mas que por motivos financeiros foi extinta em 1963.

Os anos de 1958 a 1964 foram marcados por ações em que "a educação de adultos era entendida a partir de uma visão das causas do analfabetismo, como uma educação de base, articulada com as "reformas de base" defendida pelo governo popular/populista de João Goulart" (GADOTI; ROMÃO, 2006, p. 36).

Com o $2^{\circ}$ Congresso Nacional de Educação de Adultos, nasce a ideia de um programa permanente de Educação de Adultos. Em decorrência desse Congresso surge o Plano Nacional de Alfabetização de Adultos (PNAA), dirigido por Paulo Freire, extinto pelo Golpe de Estado (CODATO, 2004)7 em 1964, juntamente com os demais movimentos de alfabetização de adultos vinculados à ideia de fortalecimento popular. Segundo Di Pierro, Joia e Ribeiro (2001) sobre os princípios que orientavam estes movimentos:

0 paradigma pedagógico que então se gestava preconizava com centralidade o diálogo como princípio educativo e a assunção por parte dos educandos adultos, de seu papel de sujeitos de aprendizagem, de produção de cultura e de transformação do mundo (DI PIERRO; JOIA; RIBEIRO, 2001, p. 60).

Porém, ainda neste cerne, o Movimento de Educação de Base (MEB) que tinha como propósito, além da educação, abrir caminhos para a libertação de milhares de homens e mulheres que ao viverem na ignorância tornavam-se vulneráveis aos desmandos ditatoriais sobreviveu até 1969 devido à sua ligação com a Igreja (GADOTI; ROMÃO, 2006).

No ano de 1965, em oposição às ideias de Paulo Freire, surgiu em Recife a Cruzada Ação Básica Cristã (ABC), de caráter conservador e semioficial (HADDAD; DI PIERRO, 2000). Em 1967, o Movimento Brasileiro de Alfabetização (MOBRAL) e a Cruzada $A B C$, constituíram-se em movimentos concebidos com o fim básico de controle político da população, através da centralização das ações e orientações, supervisão pedagógica e produção de materiais didáticos (DI PIERRO; JOIA; RIBEIRO, 2001).

Em 1971 a Lei no. 5.692 (BRASIL, 1971) regulamenta o Ensino Supletivo (esse grau de ensino visa a contemplar os jovens adultos) como proposta de reposição de escolaridade, o suprimento como aperfeiçoamento, a aprendizagem e qualificação sinalizando para a profissionalização, foram contemplados com um capítulo específico na legislação

\footnotetext{
7 Mais que uma crise institucional (seja política, seja militar, seja parlamentar), ou uma crise econômica, a crise de 1964 é a expressão-limite da luta de classes no Brasil.
} 
oficial. Na sequência, o Parecer do Conselho Federal de Educação n. 699, publicado em 28 de julho de 1972 e o documento "Política para o Ensino Supletivo" que tiveram como relator Valnir Chagas, explicitaram as características desta Modalidade de Ensino.

[...] o Ensino Supletivo visou se constituir em "uma nova concepção de escola", em uma "nova linha de escolarização não-formal, pela primeira vez assim entendida no Brasil e sistematizada em capitulo especial de uma lei de diretrizes nacionais", e, segundo Valnir Chagas, poderia modernizar o Ensino Regular por seu exemplo demonstrativo e pela interpenetração esperada entre os dois sistemas (HADDAD; DI PIERRO, 2000, p. 116).

Ainda considerando o Ensino Supletivo, Haddad e Di Pierro (2000, p. 117) enfatizam que:

\begin{abstract}
Portanto, o Ensino Supletivo se propunha a recuperar o atraso, reciclar o presente, formando uma mão-de-obra que contribuísse no esforço para o desenvolvimento nacional, através de um novo modelo de escola.
\end{abstract}

Na visão dos legisladores, o Ensino Supletivo nasceu para reorganizar o antigo exame de madureza, que facilitava a certificação e propiciava uma pressão por vagas nos graus seguintes, em especial no universitário. Segundo o Parecer 699, era necessária, também, a ampliação da oferta de formação profissional para "uma clientela já engajada na força de trabalho ou a ela destinada em curto prazo". Por fim, foram agregados cursos fundados na concepção de educação permanente, buscando responder aos objetivos de uma "escolarização menos formal e 'mais aberta"'.

A partir de 1985 com a redemocratização do país, o Movimento Brasileiro de Alfabetização (MOBRAL) é extinto e ocupa seu lugar a Fundação EDUCAR, com as mesmas características do MOBRAL, porém sem o suporte financeiro necessário para a sua manutenção. Com a extinção da Fundação EDUCAR em 1990 ocorre a descentralização política da EJA, transferindo a responsabilidade pública dos programas de alfabetização e pós-alfabetização aos municípios. Segundo Haddad e Di Pierro (2000, p. 121), ao comentar sobre a extinção da Fundação:

Representa um marco no processo de descentralização da escolarização básica de jovens e adultos, que representou a transferência direta de responsabilidade pública dos programas de alfabetização e pós-alfabetização de jovens e adultos da União para os municípios. Desde então, a União já não participa diretamente da prestação de serviços educativos, enquanto a participação relativa dos municípios na matrícula do ensino básico de jovens e adultos tendeu ao crescimento contínuo [...]. 
Em 1989 foram convocados especialistas para a discussão do Ano Internacional da Alfabetização definido pela UNESCO para 1990. Data em que foi fundada a Comissão Nacional para o Ano Internacional da Alfabetização (CNAIA), porém a mesma é desarticulada pela ocasião da extinção da Fundação EDUCAR. No ano Internacional da Alfabetização (1990), vários debates foram realizados por instituições governamentais e não governamentais no sentido de encontrar estratégias para erradicar o analfabetismo no Brasil.

0 governo Fernando Collor de Mello lança o Programa Nacional de Alfabetização e Cidadania (PNAC), que tinha como objetivo reduzir 70\% do número de analfabetos do país em cinco anos que, em termos quantitativos chegava a 17.762.629 em 1990. Para atingir esse objetivo criou-se a Comissão do Programa Nacional da Alfabetização e Cidadania que, aos poucos, foi-se desarticulando, tendo em vista, a completa fragmentação e desvinculação do Programa e da Comissão na liberação de recursos (MACHADO, 1998).

A década de 90 foi marcada pela relativização nos planos cultural, jurídico e político - dos direitos educativos das pessoas jovens e adultas conquistadas em momentos anteriores, e a descentralização da problemática, bem como a situação marginal da EJA nas políticas públicas do país (HADDAD; DI PIERRO, 2000). Nesta década, a articulação em torno da Lei de Diretrizes e Bases da Educação Nacional (BRASIL, 1996), reafirmou a institucionalização da modalidade EJA substituindo a denominação Ensino Supletivo por EJA. Esta mudança de denominação é fato controverso para alguns autores:

A mudança de ensino supletivo para educação de jovens e adultos não é uma mera atualização vocabular. Houve um alargamento do conceito ao mudar a expressão de ensino para educação. Enquanto o termo "ensino" se restringe à mera instrução, o termo "educação" é muito mais amplo compreendendo os diversos processos de formação (SOARES, 2002, p. 12).

Correlações também podem ser encontradas em relação à Declaração de Hamburgo (UNESCO, 1997, p. 2), quando esta:

[...] apresenta novos desafios às práticas existentes, devido à exigência de um maior relacionamento entre os sistemas formais e os não-formais e de inovação, além de criatividade e flexibilidade. Tais desafios devem ser encarados mediante novos enfoques, dentro do contexto da educação continuada durante a vida. Promover a educação de adultos, usar a mídia e a publicidade local e oferecer orientação imparcial é responsabilidade de governos e de toda a sociedade civil. 0 objetivo principal dever ser a criação de uma sociedade instruída e comprometida com a justiça social e o bem-estar geral. 
Por outro lado, a Lei no. 9.394 (BRASIL, 1996) em seu artigo 38 faz referência aos cursos e exames supletivos e, assim, continua a ideia da suplência, de compensação e de correção de escolaridade. A redução das idades mínimas de 18 para 15 anos para o ensino fundamental e de 21 para 18 anos para o ensino médio vem corroborar com a desqualificação desta modalidade de ensino, privilegiando certificação em detrimento dos processos pedagógicos (RUMMERT; VENTURA, 2007).

Em 1997, contrapondo-se a este discurso, a Declaração de Hamburgo sobre a Educação de Adultos, resultado da V Conferência Internacional para a Educação de Adultos (CONFINTEA) enfatiza que:

A educação de adultos torna-se mais que um direito: é a chave para o século XXI; é tanto conseqüência do exercício da cidadania como uma plena participação na sociedade. Além do mais, é um poderoso argumento em favor do desenvolvimento ecológico sustentável, da democracia, da justiça, da igualdade entre os sexos, do desenvolvimento socioeconômico e científico, além de um requisito fundamental para a construção de um mundo onde a violência cede lugar ao diálogo e à cultura de paz baseada na justiça (UNESCO, 1997, p.1).

Igualmente o Parecer CNE/CEB no 11 (CONSELHO NACIONAL DE EDUCAÇÃO, 2000), das Diretrizes Curriculares para a EJA descreve essa modalidade de ensino por suas funções: reparadora, pela restauração de um direito negado; equalizadora, de modo a garantir uma redistribuição e alocação em vista de mais igualdade na forma pela qual se distribuem os bens sociais; e qualificadora, no sentido de atualização de conhecimentos por toda a vida.

A concepção legal da EJA não tem interferido nas políticas públicas para essa modalidade de ensino da qual continua sendo excluída. Um exemplo desse argumento é a criação do Fundo de Manutenção e Desenvolvimento do Ensino Fundamental e valorização do Magistério (FUNDEF) que contava os alunos do ensino fundamental para o retorno dos recursos (verbas de investimento em educação), mas não considerava os alunos da EJA. 0 afastamento da União nas políticas públicas de EJA, transferindo a responsabilidade para Estados e Municípios, proporcionou iniciativas de cunho popular caracterizando uma pulverização de programas na tentativa de minimizar a problemática de EJA no Brasil (HADDAD; DI PIERRO, 2000).

No que diz respeito à relação entre Estado e educação popular surgem duas tendências teórico-práticas: uma maniqueísta, que não admite o Estado como parceiro da educação popular e defende uma nova educação popular e uma nova escola pública com caráter popular (GADOTI; ROMÃO, 2006). Outra integracionista que propõe parceria de colaboração entre Estado, igreja, empresariado, sociedade civil etc. Esta sugere a escolarização e a extensão da escola das elites para a população (PAIVA, 1970 apud GADOTTI; ROMÃO, 2006). 
0 governo do então Presidente Luiz Inácio Lula da Silva (2003 a 2006), sinalizou com iniciativas para as políticas públicas de EJA com maior ênfase do que o tratamento de governos anteriores. A criação do Programa Brasil Alfabetizado envolveu concomitantemente a geração de suas três vertentes de caráter primordialmente social para a modalidade de EJA. Primeiro, o Projeto Escola de Fábrica que oferece cursos de formação profissional com duração mínima de $600 \mathrm{~h}$ para jovens de 15 a 21 anos.

Segundo, o PROJOVEM que está voltado ao segmento juvenil de 18 a 24 anos, com escolaridade superior a $4^{\text {a }}$ série (atualmente o $5^{\circ}$ ano), mas que não tenha concluído o ensino fundamental e que não tenha vínculo formal de trabalho. Este tem como enfoque central a qualificação para o trabalho unindo a implementação de ações comunitárias (CONSELHO NACIONAL DE EDUCAÇÃO, 2006).

Terceiro, o Programa de Integração da Educação Profissional ao Ensino Médio para Jovens e Adultos (PROEJA) voltado à educação profissional técnica em nivel de ensino médio. Estas vertentes apesar de buscarem a escolarização dos adultos (RUMMERT, 2007) e constituirem iniciativas ampliadas para as políticas de EJA, estabelecem ações no sentido da profissionalização, mas reforçam a idéia de fragmentação de programas, em que a certificação é meta na busca da universalização da educação e erradicação do analfabetismo sem, contudo, uma perspectiva de continuidade caracterizando a formação inicial (RUMMERT; VENTURA, 2007). Faz-se presente aí, 0 caráter do capital humano ${ }^{8}$ assinalando a força do trabalho tomada como mercadoria na produção de capital econômico (GENTILI, 1998).

\section{Público de EJA}

"Os que não tiveram acesso à educação na idade própria" (BRASIL, 1996). 0 público de EJA é constituído por jovens e adultos, ou os "não crianças" (OLIVEIRA, 1999, p. 59). Por essa singularidade nos dirigimos a uma faixa etária diferenciada, com características próprias. Primeiramente jovens e adultos não podem ser tratados como crianças. São pessoas que não tiveram infância, ou tiveram uma infância frustrada, têm vergonha de si mesmos, possuem complexo de inferioridade diante da sociedade que os oprime e os discrimina (FREIRE, 1987). 0 fato de serem excluídos da escola os coloca à margem do mercado de trabalho pela sua condição de não escolarizado e, também, pertencente a determinados grupos culturais com singularidades marcantes. 0 migrante constitui uma grande parte desse público e, pelo fato de ser migrante, não concluiu a sua trajetória escolar. Nesta perspectiva, o perfil do público de EJA caracteriza-se na contraposição ao estereótipo de adulto que segue o curso regular de escolarização (OLIVEIRA, 1999).

\footnotetext{
${ }^{8}$ Capital humano: conhecimentos que aumentam a capacidade de trabalho (SHULTZ, 1962).
} 
O jovem retorna a EJA em uma busca de certificação o que teoricamente o colocaria no mercado de trabalho e teria o seu lugar na sociedade garantido, tendo com isso o resgate da auto-estima e passando a ser visto como um cidadão comum. Para tanto, confia que sua entrada no mundo do trabalho lhe proporcione condições melhores de vida, e pensa até na possibilidade de formação de sua própria família (PALÁCIOS, 1995 apud OLIVEIRA, 1999). 0 adulto já inserido no mundo do trabalho traz consigo uma história mais longa e acumula reflexões sobre o mundo externo (OLIVEIRA, 1999).

\section{Políticas públicas e EJA: como se relacionam?}

A maioria das iniciativas de EJA, até então, surgiram com a participação do estado. A necessidade de prestar contas à comunidade internacional sobre os indices de analfabetismo fez com que o estado buscasse encontrar soluções imediatas para resolver o problema instalado e erradicar o analfabetismo. Manifestações populares apareceram indo de encontro às iniciativas do Estado. Com isso, a divergência de ideias sobre um mesmo tema, formas de abordagens e iniciativas pedagógicas com traço marcante do grupo interessado surgem na tentativa de instituir programas que solucionem os problemas do grupo social em questão. Da parte do estado ficava clara a intencionalidade política, a busca do analfabeto para cumprir suas obrigações eleitorais, demonstrando também fragilidades nas políticas de governo, falta de políticas de base e caracterização expressa de redimensionamento e renovação de propostas a cada plataforma de governo (PAIVA, 1973). Os movimentos populares apresentavam as seguintes características: luta por seus direitos civis, promoção da conscientização cidadã, valorização cultural com ênfase nos aspectos culturais locais e a busca da solução de problemas locais de interesse do grupo.

$\mathrm{Na}$ tentativa de caracterizar as peculiaridades locais e identificar as necessidades específicas de um grupo social, para entendê-lo e então atuar efetivamente na perspectiva da educação popular, urge compreender o homem como:

[...] um ser de relações "temporalizado e situado", ontologicamente inacabado - sujeito por vocação, objeto por distorção -, descobre que não só está na realidade, mas também que estão com ela [...] o homem e somente o homem é capaz de transcender, de discernir, de separar órbitas existentes diferentes, de distinguir o "ser" do "não ser"; de travar relações incorpóreas. Na capacidade de discernir estará a raiz da consciência de sua temporalidade, obtida precisamente quando atravessando o tempo, de certa forma até então unidimensional, alcança o ontem, reconhece o hoje e descobre o amanhã (FREIRE, 1983, p. 62).

Em contraponto a Paulo Freire e a educação popular, entra a qualificação profissional definida nas Diretrizes Nacionais por: "A EJA das camadas populares tem 
de, necessariamente, assumir como princípio ordenador, o mundo do trabalho" (CONSELHO NACIONAL DE EDUCAÇÃO, 2000 apud GADOTTI; ROMÃO, 2006, p. 122). Desta forma, nossa análise permite caracterizar quatro pilares de cunho político que tendem a homogeneização na EJA. Em primeiro lugar, a certificação apenas no sentido da escolarização, ou seja, conclusão de determinado grau de ensino. Em segundo lugar parte-se para a idéia de empregabilidade. Teoricamente com um certificado o jovem ou adulto pode inserir-se no mercado de trabalho. Em terceiro lugar, o reconhecimento social que o levaria para o quarto pilar que constituiria a elevação e afirmação de sua autoestima. Esses quatro pilares nos remetem à ideologia capitalista no campo do messianismo pedagógico da teoria do capital humano (ROSSI, 1980). 0 cerne da teoria do capital humano empreende a ideia do ganho de eficiência e aumento na capacidade de produzir do trabalhador. A essa capacidade de produzir trabalho se acrescenta a educação como forma de acréscimo à capacidade produtiva. Deste modo:

[...] uma parte não pequena dos baixos ingressos de muitos negros, porto-riquenhos, mexicanos, elementos indígenas [...] e de alguns dos nossos trabalhadores mais velhos, reflete o fracasso de ter investido em sua saúde e educação [...] a educação serve para o desempenho no mercado e sua expansão potencializa o crescimento econômico. (SCHULTZ, 1962, p. 43).

Assumidos estes pressupostos, a universalização da escolaridade tornar-se-ia incompativel com um arranjo econômico onde a diferença de classe econômica persiste. Não é possível que se jogue na educação os riscos de assumir o ônus da desigualdade social sem que as relações entre os programas afinem-se numa só linguagem. A exploração econômica representa o suporte e a razão de ser de todo processo hegemônico onde a dominação se exerce através de mecanismos aparentemente mais democráticos e certamente mais eficientes, entre eles regimes políticos conservadores e autoritários (ROSSI, 1980). Estendendo a escolaridade num país capitalista com grandes desniveis de renda, o que se conseguiria obter é um povo bem educado, mas pobre. A igualdade de oportunidades estaria calcada na meritocracia, segundo Carnoy (1975 apud ROSSI, 1980): "o individuo é considerado como tendo "livre escolha" capaz de ir tão alto quanto sua motivação.

Nas políticas públicas aligeiradas que observamos hoje no Brasil, a modalidade de ensino que constitui a EJA apresenta-se como um direito do cidadão, tentando afastar-se da ideia de compensação e assumindo a reparação e equidade, aprendizagem e qualificação permanentes e não de caráter suplementar, mas fundamental. Nesta ótica defronta-se com uma flagrante contradição entre o poder econômico e o enriquecimento sociocultural na possibilidade da transformação do trabalhador como detentor de seu próprio capital humano (RUMMERT, 2007). 


\section{Imperativo do fracasso...}

Desde a Declaração Mundial sobre a Educação para Todos e o Plano de Ação para Satisfazer as Necessidades Básicas de Aprendizagens, documentos assinados pelo Brasil na Conferência Mundial sobre Educação para Todos em Jomtien, na Tailândia em 1990, que falta por parte dos governos brasileiros vontade política para enfrentar os problemas da educação (GADOTTI; ROMÃO, 2006).

Gadotti e Romão (2006) alertam para o número de analfabetos em todo o mundo que tem aumentado, segundo a UNESCO, de 742 milhões em 1970 para 884 milhões em 1990. 0 Brasil contribui generosamente para esta estatística: de 1983 até agora o número de analfabetos com 15 anos ou mais aumentou de 17.204.041 para 17.587.580 (GADOTTI; ROMÃO, 2006).

Apesar de a Constituição definir a educação como um direito de todos, o que observamos são programas fragmentados com problemas de concepção pedagógica e metodológica. Neste âmbito, muitos programas surgem como alternativas assistencialistas de combate a exclusão social, com propostas pedagógicas que sugerem uma forma universalizada de trabalho sem levar em conta as peculiaridades locais de cada comunidade, ou seja, contextos e conteúdos que abrangem a diversidade étnica e cultural de nosso país desconsiderando as características locais das comunidades escolares. A alfabetização de adultos por si só não resolve (GADOTTI; ROMÃO, 2006).

Há que se preocupar com o cidadão que busca a EJA nos diferentes espaços, tanto na cidade, como no meio rural, pois as formas de ensinar se constituem em desafios, considerando o compromisso social e profissional com a comunidade.

Por outro lado, a escolarização exige bem mais que o educador possa imaginar, é processo complexo onde o todo é mais que a soma das partes. Neste, o educador é um mediador da apropriação do saber por parte do educando (GADOTI; ROMÃO, 2006). É preciso que o mesmo seja capaz de, estar no mundo e saber-se nele (FREIRE, 1983), ou seja, não basta ser competente para ser educador. Ainda é necessário refletir sobre o contexto em que está inserido e sobre o fato de que o adulto não pode ser tratado como criança: "Há muitos anos que a Andragogia nos tem ensinado que a realidade do adulto é diferente da realidade da criança, mas ainda não incorporamos esse princípio nas nossas metodologias." (FURTER, 1974 apud GADOTT; ROMÃO, 2006, p. 39).

Nesta perspectiva, o sujeito educador, precisa de uma sólida formação política e social, para atuar frente às propostas pedagógicas incoerentes com o contexto em que se desenvolvem os programas de EJA. Concordamos com Romão (2006, p. 61) que: 
O Professor é um educador [...] E não querendo sê-lo, torna se um deseducador. Professor-Instrutor qualquer um pode ser dado que é possível ensinar relativamente com o que se sabe; mas Professor/Educador nem todos podem ser, uma vez que só se educa o que se é.

A complexidade da definição dos termos associados à EJA e a caracterização do público desta modalidade fizeram com que uma imensa confusão se instalasse através do tempo culminando em tentativas frustradas de solucionar um problema que parecia emperrar o desenvolvimento do país: a escolarização de jovens e adultos. 0 retrato apresentado por esta análise são políticas públicas não aliadas a iniciativas populares, ou seja, uma dicotomia de enfrentamento entre o popular e o formal. Segundo Haddad e Di Pierro (2000, p. 108):

[...] a EJA sempre compreendeu um conjunto diverso de processos e práticas formais e informais relacionadas à aquisição ou ampliação de conhecimentos, de competências técnicas e profissionais ou de habilidades socioculturais [...] quase todos os domínios da vida social.

Uma reflexão sobre a educação aponta para a educação de adultos como resultado da ineficácia do Estado em garantir, por meio de políticas públicas adequadas, a oferta e a permanência da criança e do adolescente na escola. Sendo assim, as iniciativas em EJA, em sua grande maioria, caminham na marginalidade do processo educativo brasileiro e as questões mais incisivas no tocante a esta afirmação dizem respeito às propostas de governo criadas de acordo com as necessidades políticas de cada sistema ideologicamente dominante.

\section{Considerações finais}

Não se pode refletir sobre a Educação de Jovens e Adultos sem relacionála diretamente à forma como a sociedade está estruturada. Os cursos de alfabetização de adultos existem, exatamente, pela falta objetiva de oportunidades educacionais que garantam às crianças o acesso à escola, bem como à sua permanência, haja vista os altos índices de evasão e repetência evidenciados nas estatísticas sociais.

No cenário atual, a sociedade vê a juventude e o adulto analfabeto como sinônimo de problema e motivo de preocupação. Especificamente, a juventude é a fase mais marcada por contradições de elementos de emancipação e subordinação sempre em choque e negociação. 0 adulto analfabeto defronta-se com a sociedade letrada e necessita de, no mínimo, saber enfrentar a tecnologia da comunicação para que, como cidadão, saiba lutar por seus direitos, pois ao contrário, torna-se vitima de um sistema excludente e pensado para poucos. 
Com um público específico que traz consigo sequelas de experiências frustradas ao longo da vida, 0 adulto chega à EJA com uma bagagem cultural diversificada, habilidades inúmeras, conhecimentos acumulados e reflexões sobre o seu mundo. Muitos se encontram humilhados pela condição de excluidos da escola por diferentes razões: necessidade de trabalho, reprovações sucessivas, por não se terem adaptado às normas da escola, por não terem conseguido aprender o que necessitam com urgência aprender o necessário para sobreviver neste mundo científico e tecnológico em que vivem. Chegam e encontram a mesma escola que os excluiu há anos com propostas pedagógicas que não contemplam as suas expectativas e escolas com regras específicas e generalizadas. Este, além de outros aspectos leva ao alto índice de evasão observada nos programas de EJA na atualidade. Esse fracasso pode ser explicado, principalmente, por problemas de concepção epistemológica e pedagógica entre o concebido pelas propostas oficiais e o vivido por esta comunidade no âmbito escolar.

Em meio a um discurso progressista, tem-se conferido à educação escolar a formação do cidadão-trabalhador, centralizando o desenvolvimento socioeconômico na educação, retirando, portanto, dos órgãos governamentais as obrigações educacionais. 0 progressivo descompromisso do governo juntamente com as politicas neoliberais busca centralizar, nas políticas educacionais, a lógica do mercado econômico. Sendo assim, a educação se caracteriza como uma concepção produtivista exigindo do "aluno" competências sociais e cognitivas que marcam um perfil profissional desejado pela sociedade.

0 predomínio de uma concepção produtivista nas atuais políticas educacionais, ao mesmo tempo em que se baseia no discurso da equidade e democratização, estimula a exclusão de determinadas modalidades de ensino por meio de desobrigação governamental. É dessa forma que a educação de jovens e adultos vem sendo dimensionada no contexto social. 


\section{Referências}

AMARAL, N. C. Um novo Fundef: as idéias de Anísio Teixeira. Educação $\&$ Sociedade, Campinas, SP, v. 22, n. 75, p. 277-290, 2001.

BARDIN, I. Análise de conteúdo. Lisboa: Edições 70, 1994.

BEISIEGEL, C. R. Mudança social e mudança educacional. In: Estado e educação popular: um estudo sobre educação de adultos. São Paulo: Pioneira, 1974.

BRASIL. Lei no. 5.692, de 11 de agosto de 1971. Fixa Diretrizes e Bases para o ensino de $1^{\circ} \mathrm{e}$ $2^{\circ}$ graus, e dá outras providências. Diário Oficial da União, Brasília, DF, 12 ago. 1971.

BRASIL. Lei n. 9.394, de 20 de dezembro de 1996. Estabelece as diretrizes e bases da educação nacional. Diário Oficial da União, Brasília, DF, 23 dez. 1996.

CODATO, A. N. 0 golpe de 1964: luta de classes no Brasil: a propósito de "Jango, por Silvio Tendle. Revista Espaço Acadêmico, Maringá, PR, n. 36, maio 2004. Disponivel em: <http://www.espacoacademico.com.br>. Acesso em: 13 jan. 2008.

CONSELHO FEDERAL DE EDUCAÇÃO. Parecer nº. 699, de 28 de julho de 1972. Ensino supletivo. Brasília, DF, 1972.

CONSELHO NACIONAL DE EDUCAÇÃO. Câmara de Educação Básica. Parecer CNE/ CEB n. 11, de 10 de maio de 2000. Diretrizes Curriculares para a Educação de Jovens e Adultos. Diário Oficial da União, Brasília, DF, 9 jun. 2000. Seção 1e, p. 15.

. Parecer CNE/CEB n. 37, de 7 de julho de 2006. Diretrizes e procedimentos técnico-pedagógicos para a implementação do ProJovem - Programa Nacional de Inclusão de Jovens. Diário Oficial da União, Brasília, DF, 4 ago. 2006.

DI PIERRO, M. C.; JOIA, 0. ; RIBEIRO, V. M. Visões da educação de jovens e adultos no Brasil. Caderno Cedes, Campinas, SP, n. 55, p. 58-77. 2001.

FÁVERO, 0.; RUMMERT, S. M.; VARGAS, S. M. Formação de profissionais para a educação de jovens e adultos trabalhadores. Educação em Revista, Belo Horizonte, n. 30, p. 39-49, 1999.

FERNANDES, F. Em defesa da escola pública. Revista Brasileira de Estudos Pedagógicos, Brasília, DF, v. 33, n. 77, p. 3-15, jan./mar. 1960.

FREIRE, P. Ação cultural para a liberdade e outros escritos. 10. ed. São Paulo: Paz e Terra, 2002. 
FREIRE, P. Educação e mudança. 7. ed. Rio de Janeiro: Paz e Terra, 1983.

FREIRE. P. Pedagogia do oprimido. 17. ed. Rio de Janeiro: Paz e Terra, 1987.

FRIGOTTO, G.; CIAVATTA, M. (Org.). Teoria e educação no labirinto do capital. Petrópolis, RJ: Vozes, 2001.

FRIGOTTO, G.; CIAVATTA, M.; RAMOS, M. A política de educação profissional no Governo Lula: um percurso histórico controvertido. Educação \& Sociedade, Campinas, SP, v. 26, n. 92, p. 1087-1113, 2005.

GADOTI, M. Saber aprender: um olhar sobre Paulo Freire e as perspectivas atuais da educação. In: CONGRESSO INTERNACIONAL, 2000, Évora. Um olhar sobre Paulo Freire: trabalhos apresentados... Évora, PT: Universidade de Évora, 2000.

GADOTTI, M.; ROMÃO, J. E. Educação de jovens e adultos: teoria prática e proposta. 8. ed. São Paulo: Cortez, 2006.

GENTILI, P. 0 que há de novo nas "novas" formas de exclusão educacional? neoliberalismo, trabalho e educação. In: . A falsificação do consenso: simulação e imposição na reforma educacional do neoliberalismo. Petrópolis, RJ: Vozes, 1998.

HADDAD, S.; DI PIERRO, M. C. Escolarização de jovens e adultos. Revista Brasileira de Educação, São Paulo, n. 14, p. 108-130, 2000.

KARAGIANNIS, A.; STAINBACK, W.; STAINBACK, S. Fundamentos do ensino inclusivo. In: STAINBACK, S.; STAINBACK, W. In: Inclusão: um guia para educadores. Trad. Magda França Lopes. Porto Alegre: Artes Médicas Sul, 1999.

LOPES, S.; SOUZA, L. S. EJA: uma educação possivel ou mera utopia?. Revista Alfabetização Solidária (Alfasol), São Paulo, v. 5, 2005. Disponivel em: $<$ http://www.cereja.org.br/pdf/revista_v/Revista_SelvaPLopes.pdf >. Acesso em: 25 out. 2007.

MACHADO, M. M. A prática e a formação de professores na EJA: uma análise de dissertações e teses produzidas no período de 1986 a 1998. In: REUNIÃO ANUAL DA ANPED, 23., 2000, Caxambu. Trabalhos apresentados... São Paulo: ANPED, 2000.

. A trajetória da EJA na década de 90: políticas públicas sendo substituídas por solidariedade. In: REUNIÃO ANUAL DA ANPED, 21., 1998, Caxambu. Trabalhos apresentados... São Paulo: ANPED, 1998. 
OLIVEIRA, M. K. Jovens e adultos como sujeitos de conhecimento e aprendizagem. Revista Brasileira de Educação, Rio de Janeiro, n. 12, p. 59-73, 1999.

OLIVEIRA, M. C. C.; ALMEIDA, S. I. B. Uma proposta temática para a educação de jovens e adultos. In: COLÓQUIO INTERNACIONAL PAULO FREIRE, 5., 2005, Recife. Trabalhos apresentados... Recife, PE: Centro Paulo Freire, 2005.

PAIVA, V. Educação popular e educação de adultos. São Paulo: Loyola 1973. v. 1. (Temas Brasileiros, 2).

PALACIOS, J. Introdução à psicologia evolutiva: história, conceitos básicos e metodologia. In: COLL, C.; PALACIOS, J.; MARCHESI, A. (Org.) Desenvolvimento psicológico e educação: psicologia evolutiva. Porto Alegre: Artes Médicas, 1995.

PILLETI, C. História da educação. 2. ed. São Paulo: Ática, 1988.

ROMÃO, J. E. Compromisso do educador de jovens e adultos. In: GADOTI, M.; ROMÃO, J. E. (Org.). Educação de jovens e adultos: teoria prática e proposta. São Paulo: Cortez, 2006. v. 5.

ROSSI. W. G. Capitalismo e educação: contribuição ao estudo crítico da economia da educação capitalista. 2. ed. São Paulo: Moraes, 1980.

RUMMERT, S. M. A educação de jovens e adultos trabalhadores brasileiros no século XXI: o "novo" que reitera antiga destituição de direitos. Revista de Ciências da Educação, Lorena, SP, n. 2, p. 35-50, 2007.

RUMMERT, S. M.; VENTURA, J. P. Políticas públicas para educação de jovens e adultos no Brasil: a permanente (re) construção da subalternidade: considerações sobre os Programas Brasil Alfabetizado e Fazendo Escola. Educar em Revista, Curitiba, n. 29, p. 29-45, 2007.

SANTOS, A. R. A Igreja Católica, a mídia e a educação popular: o MEB: a utopia destruída. PCLA, v. 3, n. 4, jul./ago./set. 2002. Disponivel em:

<http://www2.metodista.br/unesco/PCLA/revista12/revista12.htm >. Acesso em: 19 jul. 2010.

SENAI. História. Brasilia, DF, [2007?]. Disponível em: <www.senai.br>. Acesso em: 20 dez. 2007.

SOARES, L. J. G. Educação de jovens e adultos. Rio de Janeiro: DPCtA, 2002. 
SOUZA, C. M. Nenhum brasileiro sem escola: projetos de educação de adultos do Estado desenvolvimentista. Dissertação (Mestrado em História) - Faculdade de Filosofia, Letras e Ciências Humanas, Universidade de São Paulo, São Paulo, 1999.

SHULTZ, T. O valor econômico do saber. Rio de Janeiro: Zahar, 1962.

UNESCO. Declaração de Hamburgo sobre a educação de adultos e plano de ação para o futuro. In: CONFERÊNCIA INTERNACIONAL SOBRE A EDUCAÇÃO DE ADULTOS, 1997, Hamburgo. Anais... Hamburgo, Alemanha, 1997.

VIEIRA, M. C. Fundamentos históricos, políticos e sociais da Educação de Jovens e Adultos: aspectos históricos da educação de jovens e adultos no Brasil. Brasília, DF: UnB, CEAD, 2004.

Recebido em: 16/05/2008

Aceito para publicação: 08/03/2010 